\title{
Incidence of postoperative acute kidney injury in patients with chronic kidney disease undergoing minimally invasive valve surgery
}

\author{
Gerson D. Valdez, MD, ${ }^{\mathrm{a}}$ Christos G. Mihos, DO, ${ }^{\mathrm{a}}$ Orlando Santana, MD, ${ }^{\mathrm{a}}$ Todd B. Heimowitz, DO, ${ }^{\mathrm{a}}$ \\ Robert Goldszer, MD, ${ }^{b}$ Gervasio A. Lamas, MD, ${ }^{a}$ and Joseph Lamelas, MD $^{\mathrm{c}}$
}

\begin{abstract}
Background: We hypothesize that minimally invasive valve surgery in patients with chronic kidney disease (CKD) is superior to a conventional median sternotomy.

Methods: We retrospectively analyzed 1945 consecutive patients who underwent isolated valve surgery. Included were patients with CKD stages 2 to 5. In-hospital mortality, composite complication rates, and intensive care unit and total hospital lengths of stay of those who underwent a minimally invasive approach were compared with those who underwent a standard median sternotomy. Resource use was approximated based on intensive care unit and total hospital lengths of stay.
\end{abstract}

Results: There were 688 patients identified; 510 (74\%) underwent minimally invasive surgery, and 178 (26\%) underwent a median sternotomy. There was no significant difference in mortality. Minimally invasive surgery was associated with fewer composite complications (33.1\% vs $49.4 \%$; odds ratio, $0.5 ; P \leq .001)$, shorter intensive care unit (48 [interquartile range $\{\mathrm{IQR}\}, 33-74]$ hours vs 71 [IQR, 42-96] hours; $P<.01)$, and hospital (8 [IQR, 6-9] days vs 10 [IQR, 8-15] days; $P<.001)$ lengths of stay, and a lower incidence of acute kidney injury ( $8 \%$ vs $14.7 \%$; odds ratio, $0.5 ; P=.01$ ), compared with median sternotomy. In a multivariable analysis, minimally invasive surgery was associated with a $60 \%$ reduction in the risk of development of postoperative acute kidney injury.

Conclusions: In patients with CKD undergoing isolated valve surgery, minimally invasive valve surgery is associated with reduced postoperative complications and lower resource use. (J Thorac Cardiovasc Surg 2013;146:1488-93)

According to data published by the National Institutes of Health, more than $10 \%$ of the US population is diagnosed with chronic kidney disease (CKD), and nearly 113,000 patients will progress to end-stage renal disease each year. ${ }^{1}$ Cardiovascular disease is one of the leading causes of morbidity and mortality in this population, and the chronic inflammation, endothelial dysfunction, and metabolic disturbances seen in the progression of CKD have been strongly associated with the development of valvular heart disease.,3 Patients undergoing cardiac surgery have a 3.3 -fold increased risk of developing acute kidney injury (AKI), with a 2.3-fold increased risk of requiring dialysis, and in the past decade, the associated mortality of AKI after cardiac surgery has increased from $30 \%$ to $47 \%{ }^{4}$ In the setting of $\mathrm{CKD}$, these effects are augmented, with an increased incidence of CKD progression and late-term mortality. ${ }^{5}$

From the Columbia University Division of Cardiology at Mount Sinai Heart Institute, ${ }^{\mathrm{a}}$ Miami Beach, Fla; the Department of Internal Medicine, ${ }^{\mathrm{b}}$ Mount Sinai Medical Center, Miami Beach, Fla; and the Division of Cardiac Surgery, ${ }^{\mathrm{c}}$ Mount Sinai Heart Institute, Miami Beach, Fla.

Disclosures: Authors have nothing to disclose with regard to commercial support.

Received for publication Feb 21, 2013; revisions received June 11, 2013; accepted for publication June 27, 2013; available ahead of print Aug 23, 2013.

Address for reprints: Orlando Santana, MD, Echocardiography Laboratory, Mount

Sinai Medical Center, 4300 Alton Rd, Miami Beach, FL 33140 (E-mail:

osantana@msmc.com).

$0022-5223 / \$ 36.00$

Copyright (c) 2013 by The American Association for Thoracic Surgery

http://dx.doi.org/10.1016/j.jtcvs.2013.06.034
When compared with a median sternotomy approach, the reported benefits of minimally invasive valve surgery include decreased blood loss, reduced incidence of postoperative atrial fibrillation, shorter intensive care unit and hospital length of stays, and faster patient recovery. ${ }^{6-11}$ These findings have also been reported in such high-risk groups as elderly patients, obese patients, and those undergoing reoperative valve surgery, leading to an increased acceptance of minimally invasive surgery as a viable option to the standard median sternotomy approach. ${ }^{12-15}$ The purpose of our study was to analyze the impact of minimally invasive valve surgery on the incidence of postoperative AKI and postoperative complications in patients with stage 2 to $5 \mathrm{CKD}$. We analyzed the outcomes of patients who underwent valve surgery via a minimally invasive approach, and compared them with a cohort who underwent median sternotomy valve surgery.

\section{METHODS}

After obtaining approval from the Mount Sinai Medical Center Institutional Review Board, we retrospectively evaluated 1945 valve operations performed at our institution between January 1, 2005, and December 7, 2011, to identify patients with stage 2 to 5 CKD who underwent isolated mitral or aortic valve surgery. Excluded were patients who had concomitant coronary artery bypass graft surgery, surgery on another valve and/or ascending aorta, a history of cardiac surgery, infective endocarditis, emergency surgery, and stage $1 \mathrm{CKD}$. The estimated glomerular filtration rate (eGFR) was calculated using the modification of diet in renal 


\section{Abbreviations and Acronyms \\ AKI = acute kidney injury \\ $\mathrm{CKD}=$ chronic kidney disease \\ eGFR $=$ estimated glomerular filtration rate \\ $\mathrm{IQR}=$ interquartile range \\ RIFLE $=$ Risk, Injury, Failure, Loss, End-stage renal disease}

A left ventricular vent was inserted into the left ventricle via a purse string suture in the right superior pulmonary vein, and a retrograde cardioplegia cannula was inserted via the right atrial appendage using transesophageal echocardiographic guidance. A transverse aortotomy was performed to expose the aortic valve, and valve replacement was performed under direct vision using standard techniques.

For all procedures, cardiopulmonary bypass was initiated at $32^{\circ} \mathrm{C}$ to $36^{\circ} \mathrm{C}$ using a closed-membrane oxygenator and roller pump. Venous drainage was augmented with vacuum assistance, applying negative pressures of 30 to $70 \mathrm{~mm} \mathrm{Hg}$ as needed to decompress the right side of the heart. Transincisional direct aortic crossclamping was performed using a flexible and retractable shaft crossclamp (Novare Surgical Systems, Cupertino, Calif). One dose of antegrade cold blood cardioplegia was given to establish electromechanical arrest of the heart. Thereafter, retrograde cold blood cardioplegia was given throughout the procedure at 20- to 25-minute intervals. If retrograde cardioplegia was not possible, a cardioplegia cannula was left in the ascending aorta, or direct cannulation of the coronary ostia was performed to deliver antegrade cardioplegia. Carbon dioxide was infused into the operative field during the entire procedure. Removal of air from the heart was performed with a venting needle in the root of the aorta and under transesophageal echocardiographic guidance. After discontinuing cardiopulmonary bypass and administering protamine, decannulation was performed. A single chest tube was left in the pleural space. For pain relief, all patients had an On-Q pain relief system inserted (I-Flow Corporation, Lake Forest, Calif). Two catheters were placed in the interspace to deliver $0.25 \%$ bupivacaine for 72 hours. The thoracotomy incision was closed in the routine manner.

\section{Statistical Analyses}

Patient demographics and operative data were expressed as the mean \pm $1 \mathrm{SD}$, or median and interquartile range (IQR, or $25 \%-75 \%$ ), as appropriate. Continuous variables with a normal distribution were compared using an independent Student $t$ test and correlation coefficient, when appropriate, whereas variables that did not exhibit a normal distribution were compared using a Mann-Whitney $U$ test. A $\chi^{2}$, Pearson $\chi^{2}$, or Fisher exact test was used to compare dichotomous variables, when appropriate. A univariable analysis was performed for baseline characteristics, surgical procedural variables, postoperative outcomes, and other known risk factors that could influence the clinical outcomes. The variables with $P \leq .2$ were included in a binary logistic regression analysis to determine their independent effects. The model was assessed by the Hosmer-Lemeshow goodnessof-fit test. All statistical analyses were performed with the assistance of a statistician using SPSS, version 17 (SPSS Inc, Chicago, Ill).

\section{RESULTS}

A total of 688 patients were identified. Of these patients, 510 had valve surgery via a minimally invasive approach, and 178 underwent a median sternotomy. The patients in the minimally invasive group were older $(71.3 \pm 11.6 \mathrm{vs}$ $67.8 \pm 12$ years; $P=.001$ ), whereas those in the median sternotomy group had a higher body mass index $(27.3 \pm$ 4.8 vs $\left.28.5 \pm 5.8 \mathrm{~kg} / \mathrm{m}^{2} ; P=.03\right)$ and greater incidence of stage 5 CKD $(4 \%$ vs $1 \% ; P=.008)$. There were no other differences between the 2 groups regarding baseline characteristics (Table 1).

In the entire cohort of patients (excluding those with stage 5 CKD at baseline), 66 developed AKI and 608 did not. Those who developed AKI were significantly older, obese, had a greater incidence of median sternotomy, and had a higher baseline mean pulmonary artery

bypass. The femoral/axilary artery was cannuted with $15-19 \mathrm{Fr}$ ater phageal echocardiography was used to aid in the placement of the venous in the superior vena cava. mas accessed through the Waterston groove, then through atrial septum into the left atrium. Mitral valve repair or replacements we performed in the standard manner. For aortic valve procedures, a 5- to 6-cm right transverse skin incision was made $1 \mathrm{~cm}$ lateral to the sternum over the second to third intercostal space. In all aortic valve procedures, the second or third costochondral cartilage was transected to allow adequate exposure of the aorta and avoid fracturing the rib. At the completion of the operation, the rib was reattached to the sternum with a $1-\mathrm{cm}$ metal plate (Synthes, West Chester, Pa), and a fiber wire was placed in a figure-of-eight manner. 
TABLE 1. Baseline characteristics of the minimally invasive versus median sternotomy groups

\begin{tabular}{|c|c|c|c|}
\hline Variable & $\begin{array}{c}\text { Minimally } \\
\text { invasive } \\
(\mathbf{n}=\mathbf{5 1 0})\end{array}$ & $\begin{array}{c}\text { Median } \\
\text { sternotomy } \\
(\mathbf{n}=\mathbf{1 7 8})\end{array}$ & $\begin{array}{c}P \\
\text { value }\end{array}$ \\
\hline Age, $y$ & $71.3 \pm 11.6$ & $67.8 \pm 12$ & .001 \\
\hline Male sex & $258(51)$ & $99(56)$ & .21 \\
\hline Body mass index, $\mathrm{kg} / \mathrm{m}^{2}$ & $27.3 \pm 4.8$ & $28.5 \pm 5.8$ & .03 \\
\hline African American race & $24(5)$ & $7(4)$ & .84 \\
\hline Diabetes mellitus & $130(26)$ & $45(25)$ & .99 \\
\hline Hypertension & $393(89)$ & $151(86)$ & .63 \\
\hline Previous myocardial infarction & $95(19)$ & $26(15)$ & .29 \\
\hline Chronic obstructive pulmonary disease & $125(25)$ & $50(30)$ & .26 \\
\hline Peripheral vascular disease & $82(16)$ & $27(15)$ & .86 \\
\hline Preoperative GFR & $64.4 \pm 16$ & $63.9 \pm 18$ & .53 \\
\hline Preoperative creatinine & $1.16 \pm 0.36$ & $1.3 \pm 0.29$ & .1 \\
\hline $\begin{array}{l}\text { Stage } 2 \text { CKD (GFR, } 60-89 \mathrm{~mL} / \mathrm{min} \text { per } \\
\left.1.73 \mathrm{~m}^{2}\right)\end{array}$ & $325(64)$ & $112(63)$ & .95 \\
\hline $\begin{array}{l}\text { Stage } 3 \text { CKD (GFR, } 30-59 \mathrm{~mL} / \mathrm{min} \text { per } \\
\left.1.73 \mathrm{~m}^{2}\right)\end{array}$ & $167(33)$ & $57(32)$ & .98 \\
\hline $\begin{array}{l}\text { Stage } 4 \text { CKD (GFR, } 15-29 \mathrm{~mL} / \mathrm{min} \text { per } \\
\left.1.73 \mathrm{~m}^{2}\right)\end{array}$ & $11(2)$ & $2(1)$ & .26 \\
\hline $\begin{array}{l}\text { Stage } 5 \text { CKD }(\text { GFR, }<15 \mathrm{~mL} / \mathrm{min} \text { per } \\
\left.1.73 \mathrm{~m}^{2}\right)\end{array}$ & $7(1)$ & $7(4)$ & .008 \\
\hline Ejection fraction, $\% *$ & $58(50-60)$ & $55(43-60)$ & .09 \\
\hline Pulmonary artery pressure, $\mathrm{mm} \mathrm{Hg}$ & $27 \pm 9$ & $28 \pm 9$ & .58 \\
\hline Hematocrit, $\%$ & $38.8 \pm 4.8$ & $39.4 \pm 4.5$ & .1 \\
\hline $\begin{array}{l}\text { Predicted risk for morbidity and } \\
\text { mortality, \% }\end{array}$ & $19 \pm 9$ & $18 \pm 10$ & .14 \\
\hline Predicted risk for acute renal failure, $\%$ & $5 \pm 4$ & $4 \pm 3$ & .16 \\
\hline
\end{tabular}

Data are given as mean \pm SD or number (\%). GFR, Glomerular filtration rate; $C K D$, chronic kidney disease. ${ }^{*}$ Data are given as median (interquartile range).

pressure. However, the aortic crossclamp and cardiopulmonary bypass times did not differ between the 2 groups (Table 2).

The valve surgery consisted of 323 aortic valve replacements (236 [46\%] minimally invasive and 87 [49\%] median sternotomy; $P=.6$ ) and 365 mitral valve operations (274 [54\%] minimally invasive and 91 [51\%] median sternotomy; $P=.6)$. Of the mitral valve operations, there were $110(40 \%)$ versus $31(34 \%)$ replacements $(P=.36)$, and $164(60 \%)$ versus $60(66 \%)$ repairs $(P=.36)$, in the minimally invasive versus median sternotomy groups, respectively. The mean aortic crossclamp time was $83 \pm 27$ versus $63 \pm 30$ minutes $(P<.001)$, and the mean cardiopulmonary bypass time was $113 \pm 32$ versus $87 \pm 38$ minutes $(P<.001)$, for the minimally invasive and the median sternotomy groups, respectively. The patients undergoing minimally invasive surgery had significantly less need for packed red blood cell and fresh-frozen plasma transfusions, when compared with those who had a median sternotomy. No difference was noted in the in-hospital mortality between the minimally invasive and the median sternotomy groups $(1 \%$ vs $3 \% ; P=.17)$. However, composite postoperative complications were significantly less in the
TABLE 2. Baseline characteristics in patients with postoperative acute kidney injury versus no acute kidney injury (based on 674 patients with CKD stages 2-4)

\begin{tabular}{|c|c|c|c|}
\hline Variable & $\begin{array}{c}\text { Acute } \\
\text { kidney injury } \\
(n=66)\end{array}$ & $\begin{array}{c}\text { No acute } \\
\text { kidney injury } \\
(n=608)\end{array}$ & $\begin{array}{c}P \\
\text { value } \\
\end{array}$ \\
\hline Age, y & $72 \pm 11$ & $70 \pm 11$ & .03 \\
\hline Male sex & $30(45.4)$ & $318(52.5)$ & .41 \\
\hline Body mass index, $\mathrm{kg} / \mathrm{m}^{2}$ & $29 \pm 5.5$ & $27 \pm 5.1$ & .04 \\
\hline African American & $2(3)$ & $25(4)$ & .49 \\
\hline Diabetes mellitus & $22(34)$ & $147(24)$ & .13 \\
\hline Hypertension & $63(96)$ & $527(87)$ & .06 \\
\hline Previous myocardial infarction & $10(15)$ & $106(17)$ & .8 \\
\hline $\begin{array}{l}\text { Chronic obstructive pulmonary } \\
\text { disease }\end{array}$ & $17(26.2)$ & $153(25.2)$ & .98 \\
\hline Peripheral vascular disease & $8(12)$ & $99(16)$ & .24 \\
\hline Preoperative GFR, $\mathrm{mL} / \mathrm{min}$ per $\mathrm{m}^{2}$ & $64.6 \pm 17$ & $65.5 \pm 14.7$ & .63 \\
\hline $\begin{array}{l}\text { Preoperative serum creatinine, } \\
\mathrm{mg} / \mathrm{dL}\end{array}$ & $1.12 \pm 0.44$ & $1.1 \pm 0.3$ & .57 \\
\hline $\begin{array}{l}\text { Stage } 2 \text { CKD }(\text { GFR, } \\
\quad 60-89 \mathrm{~mL} / \mathrm{min} \text { per } 1.73 \mathrm{~m}^{2}\end{array}$ & $40(61)$ & $397(65)$ & .53 \\
\hline $\begin{array}{l}\text { Stage } 3 \text { CKD (GFR, } \\
\left.\quad 30-59 \mathrm{~mL} / \mathrm{min} \text { per } 1.73 \mathrm{~m}^{2}\right)\end{array}$ & $23(34)$ & $201(33)$ & .87 \\
\hline $\begin{array}{l}\text { Stage } 4 \text { CKD (GFR, } \\
\left.15-29 \mathrm{~mL} / \mathrm{min} \text { per } 1.73 \mathrm{~m}^{2}\right)\end{array}$ & $3(5)$ & $10(2)$ & .12 \\
\hline Ejection fraction, $\% *$ & $55(40-64)$ & $58(50-60)$ & .71 \\
\hline Pulmonary artery pressure, $\mathrm{mm} \mathrm{Hg}$ & $30.5 \pm 9.5$ & $27.1 \pm 9.2$ & .003 \\
\hline Hematocrit, $\%$ & $38.5 \pm 2.9$ & $39 \pm 4.5$ & .47 \\
\hline Median sternotomy surgery & $26(40)$ & $145(24)$ & .009 \\
\hline Aortic crossclamp time, min & $82 \pm 33$ & $78 \pm 29$ & .26 \\
\hline Cardiopulmonary bypass time, $\min$ & $113 \pm 39$ & $106 \pm 35$ & .13 \\
\hline
\end{tabular}

Data are given as mean \pm SD or number (\%) and are based on the Risk, Injury, Failure, Loss, End-stage renal disease (RIFLE) definition. Excluded in the analysis were patients with stage 5 CKD. $C K D$, Chronic kidney disease; GFR, glomerular filtration rate. $*$ Data are given as median (interquartile range)

minimally invasive group ( $33 \%$ vs $49 \% ; P<.001)$, driven by a decreased incidence of AKI, atrial fibrillation, prolonged ventilation, reintubation, and sepsis. The intensive care unit and total hospital lengths of stay were 48 (IQR, 33-74) hours versus 71 (IQR, 42-96) hours $(P<.01)$ and 8 (IQR, 6-9) days versus 10 (IQR, 8-15) days $(P<.001)$ for the minimally invasive and the median sternotomy groups, respectively (Table 3, Figure 1).

Among the patients who developed postoperative AKI, when compared with those who did not develop AKI, there was a higher in-hospital mortality $(8 \%$ vs $1 \% ; P<.001)$, and composite postoperative complications (64\% vs $34 \% ; P<.001)$, with a significant increase in the incidence of pneumonia, need of reintubation, sepsis, deep wound infection, and prolonged ventilation (Table 4, Figure 2). Furthermore, the patients with postoperative AKI had a median intensive care unit length of stay of 116 (IQR, 60-317) hours versus 49 (IQR, 46-77) hours $(P<.001)$ and a median total hospital length of stay of 14 (IQR, 10-18) days versus 8 (IQR, 6-10) days $(P<.001)$. 
TABLE 3. Operative and postoperative outcomes in patients undergoing minimally invasive versus median sternotomy valve surgery

\begin{tabular}{|c|c|c|c|}
\hline Variable & $\begin{array}{c}\text { Minimally } \\
\text { invasive } \\
(\mathbf{n}=\mathbf{5 1 0})\end{array}$ & $\begin{array}{c}\text { Median } \\
\text { sternotomy } \\
(n=178)\end{array}$ & $\begin{array}{c}P \\
\text { value }\end{array}$ \\
\hline Aortic valve replacement, No. & 236 & 87 & 6 \\
\hline Aortic crossclamp time, min & $84 \pm 28$ & $68 \pm 33$ & $<.001$ \\
\hline Cardiopulmonary bypass time, min & $111 \pm 35$ & $88 \pm 24$ & $<.001$ \\
\hline Mitral valve replacement, No. & 110 & 31 & .36 \\
\hline Aortic crossclamp time, min & $71 \pm 28$ & $67 \pm 36$ & .4 \\
\hline Cardiopulmonary bypass time, min & $100 \pm 34$ & $96 \pm 43$ & .6 \\
\hline Mitral valve repair, No. & 164 & 60 & .36 \\
\hline Aortic crossclamp time, min & $74 \pm 30$ & $53 \pm 18$ & $<.001$ \\
\hline Cardiopulmonary bypass time, min & $104 \pm 37$ & $77 \pm 26$ & $<.001$ \\
\hline $\begin{array}{l}\text { Transfusion of packed red } \\
\text { blood cells, } U^{*}\end{array}$ & $2(1-3)$ & $4(2-5)$ & $<.001$ \\
\hline $\begin{array}{l}\text { Transfusion of fresh-frozen } \\
\text { plasma, } U^{*}\end{array}$ & $0.2(0-3)$ & $2(0-4)$ & $<.001$ \\
\hline Acute kidney injury (based on STS) & $11(2)$ & $11(7)$ & .01 \\
\hline Acute kidney injury (based on RIFLE) & $40(8)$ & $25(15)$ & .01 \\
\hline Stage 1 (risk) & $26(5)$ & $13(8)$ & .32 \\
\hline Stage 2 (injury) & $11(2)$ & $9(5)$ & .31 \\
\hline Stage 3 (failure) & $3(1)$ & $3(2)$ & .17 \\
\hline Dialysis & $8(2)$ & $3(2)$ & .99 \\
\hline In-hospital mortality & $7(1)$ & $6(3)$ & .17 \\
\hline Composite complications & $169(33)$ & $88(49)$ & $<.001$ \\
\hline Atrial fibrillation & $95(19)$ & $48(27)$ & .02 \\
\hline Pneumonia & $22(4)$ & $7(4)$ & .99 \\
\hline Reintubation & $30(6)$ & $21(13)$ & .004 \\
\hline Stroke & $4(1)$ & $4(2)$ & .24 \\
\hline Sepsis & $8(2)$ & $10(6)$ & .008 \\
\hline Wound infection & $2(0.4)$ & $2(1)$ & .59 \\
\hline Prolonged ventilation & $86(17)$ & $50(28)$ & .002 \\
\hline Bleeding requiring reoperation & $12(2)$ & $5(3)$ & .95 \\
\hline Postoperative creatinine (peak), $\mathrm{mg} / \mathrm{dL}$ & $1.28 \pm 0.6$ & $1.3 \pm 0.6$ & .47 \\
\hline Intensive care unit length of stay, $\mathrm{h}^{*}$ & $48(33-74)$ & $71(42-96)$ & $<.01$ \\
\hline Hospital length of stay, $\mathrm{d}^{*}$ & $8(6-9)$ & $10(8-15)$ & $<.001$ \\
\hline
\end{tabular}

Multivariable analysis revealed that minimally invasive surgery was associated with a reduction in postoperative AKI, whereas mean pulmonary artery pressure, age older than 75 years, cardiopulmonary bypass time greater than 100 minutes, and postoperative sepsis were associated with an increased incidence of AKI (Table 5).

\section{DISCUSSION}

Because of an increased incidence of cardiovascular comorbidities and pathophysiological changes associated with chronic uremia, patients with CKD undergoing cardiac surgery have a significant risk of perioperative complications. Preoperative renal dysfunction has been an independent predictor of in-hospital mortality and poor late-term

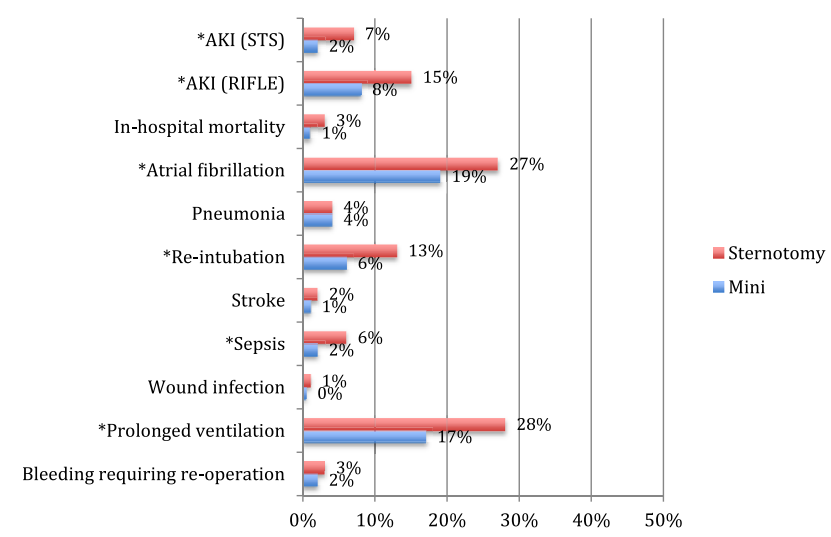

FIGURE 1. Postoperative outcomes in patients undergoing minimally invasive versus median sternotomy valve surgery. The asterisk denotes statistically significant differences between groups. AKI, Acute kidney injury; STS, Society of Thoracic Surgeons; RIFLE, Risk, Injury, Failure, Loss, End-stage renal disease; Sternotomy, median sternotomy; Mini, minimally invasive.

survival, with a nearly 5-fold increased mortality among patients undergoing valve surgery. ${ }^{17-19}$ Furthermore, the development of AKI after cardiac surgery is associated with a significant increase in healthcare costs, with small increases in serum creatinine $(>0.3 \mathrm{mg} / \mathrm{dL})$ adding nearly $\$ 10,000$ to the cost of hospitalization. ${ }^{20} \mathrm{~A}$ minimally invasive approach to valve surgery has emerged as a safe and feasible alternative to standard median sternotomy surgery in such high-risk populations as elderly patients, obese patients, and those with a history of sternotomy. ${ }^{12-15}$ Our hypothesis was that patients with CKD undergoing isolated valve surgery are at a high risk for perioperative morbidity and mortality and, thus, would benefit from a minimally invasive approach.

In the present study, despite significantly longer aortic crossclamp and cardiopulmonary bypass times in the minimally invasive group, we observed an overall $60 \%$ reduction in the risk of development of postoperative AKI. In the entire cohort, the predictors of AKI included an increased mean pulmonary artery pressure, an age of 75 years or older, a cardiopulmonary bypass time of greater than 100 minutes, and postoperative sepsis. The development of AKI was associated with an increased mortality, an increased incidence of infections, the need for reintubation, prolonged ventilation, and significantly longer intensive care unit and hospital lengths of stay. Therefore, minimally invasive valve surgery, by reducing the incidence of AKI, may have reduced the incidence of these complications, and shortened the intensive care unit and hospital lengths of stay.

The data comparing postoperative renal injury between less invasive valve surgery and standard median sternotomy surgery are limited. McCreath and colleagues ${ }^{21}$ analyzed a total of 650 patients who underwent mitral valve surgery via 
TABLE 4. Postoperative outcomes in patients with acute kidney injury versus no acute kidney injury

\begin{tabular}{lccc}
\hline \multicolumn{1}{c}{ Variable } & $\begin{array}{c}\text { Acute } \\
\text { kidney injury } \\
(\mathbf{n}=\mathbf{6 6})\end{array}$ & $\begin{array}{c}\text { No acute } \\
\text { kidney injury } \\
(\mathbf{n}=\mathbf{6 0 8})\end{array}$ & $\begin{array}{c}\boldsymbol{P} \\
\text { value }\end{array}$ \\
\hline In-hospital mortality & $5(8)$ & $7(1)$ & $<.001$ \\
Composite complications & $42(64)$ & $204(34)$ & $<.001$ \\
$\quad$ Atrial fibrillation & $16(24)$ & $123(20)$ & .54 \\
Pneumonia & $13(20)$ & $15(3)$ & $<.001$ \\
Reintubation & $5(8)$ & $7(1)$ & $<.001$ \\
Stroke & $1(2)$ & $6(1)$ & 1 \\
$\quad$ Sepsis & $10(15)$ & $8(1)$ & $<.001$ \\
$\quad$ Wound infection & $2(3)$ & $2(0.3)$ & .04 \\
$\quad$ Prolonged ventilation & $31(47)$ & $94(15)$ & $<.001$ \\
$\quad$ Bleeding requiring reoperation & $4(6)$ & $13(2)$ & .12 \\
Postoperative creatinine & $2.24 \pm 1$ & $1.17 \pm 0.38$ & $<.001$ \\
$\quad$ peak), mg/dL & & & \\
Intensive care unit length & $116(60-317)$ & $49(46-77)$ & $<.001$ \\
$\quad$ of stay, h* & & & \\
Hospital length of stay, d* & $14(10-18)$ & $8(6-10)$ & $<.001$ \\
\hline
\end{tabular}

Data are given as number $(\%)$ or mean \pm SD. Excluded in the analysis were patients with stage 5 chronic kidney disease. *Data are given as median (interquartile range).

port access $(n=467)$ or median sternotomy $(n=183)$ and found a significant reduction in postoperative renal injury and a trend toward reduced major adverse events among the port-access group. Similar results were reported by Antonic and Gersak, ${ }^{22}$ who compared 96 patients undergoing port-access mitral valve surgery with 102 patients undergoing a median sternotomy approach; they found that patients in the median sternotomy group had lower postoperative creatinine clearance and higher incidence of postoperative renal impairment. The present study validates the reported renoprotective benefits of a minimally invasive approach, and demonstrates the safety and feasibility of this technique in patients with CKD. We hypothesize that the renoprotective benefits of minimally invasive valve surgery in patients with CKD may be driven by 2 main factors. First, cardiac surgery is a powerful trigger of immune system activation,

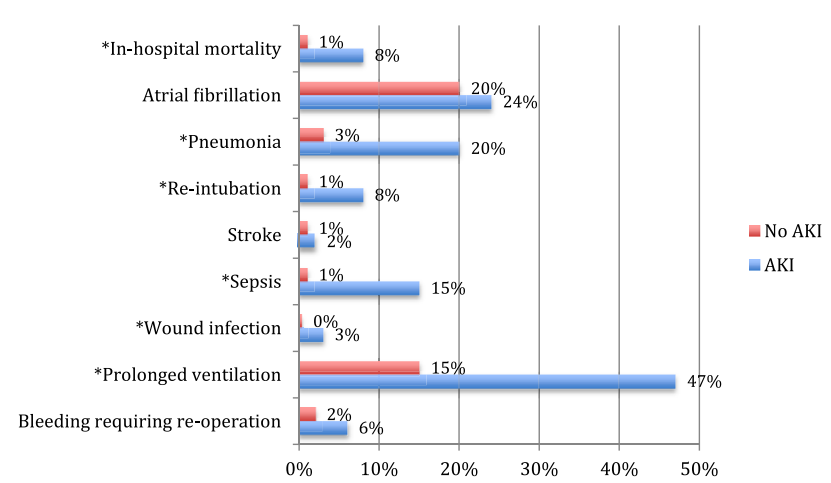

FIGURE 2. Postoperative outcomes in patients with acute kidney injury (AKI) versus no AKI. The asterisk denotes statistically significant differences between groups.
TABLE 5. Multivariable predictors of postoperative acute kidney injury (based on RIFLE criteria)

\begin{tabular}{lccc}
\hline \multicolumn{1}{c}{ Variables } & Odds Ratio & 95\% CI & $\boldsymbol{P}$ value \\
\hline Minimally invasive valve surgery & 0.4 & $0.19-0.88$ & .02 \\
Mean pulmonary artery pressure & 1.03 & $1.00-1.06$ & .03 \\
Aged $\geq 75$ y & 1.9 & $1.05-2.07$ & .03 \\
Cardiopulmonary bypass time $>100 \mathrm{~min}$ & 2.4 & $1.2-4.6$ & .007 \\
Postoperative sepsis & 6.8 & $1.9-23$ & .003 \\
\hline
\end{tabular}

Chronic kidney disease stage, diabetes mellitus, hematocrit lower than $35 \%$, units of packed red blood cells (transfusion), body mass index greater than $35 \mathrm{~kg} / \mathrm{m}^{2}$, and African American race were entered into the multivariable analysis, and were not statistically significant. RIFLE, Risk, Injury, Failure, Loss, End-stage renal disease; $C I$, confidence interval.

leading to the up-regulation of cellular immune factors and the development of systemic immune inflammatory syndrome, which increases the risk of renal injury and failure. ${ }^{23}$ By avoiding the surgical trauma and morbidity associated with a median sternotomy, a minimally invasive approach allows for a reduction in postoperative inflammation and enhanced recovery, which may provide renoprotective effects in high-risk populations, such as patients with CKD. Second, because of structural and biochemical alterations that develop in stored erythrocytes, transfusion of packed red blood cells can lead to activation of the inflammatory cascade and impaired oxygen delivery in susceptible populations, which are known contributors of renal dysfunction. ${ }^{24}$ In patients undergoing cardiac surgery, transfusion of packed red blood cells is associated with increased risk of postoperative complications, early and late mortality, and hospital length of stay and costs. ${ }^{25}$ Therefore, it is plausible that, by decreasing the incidence of blood transfusions and bleeding complications with minimally invasive valve surgery, postoperative renal injury and its associated complications may be reduced. One of the postoperative complications that was significantly reduced with the minimally invasive approach was the incidence of atrial fibrillation. We hypothesize that this reduction in atrial fibrillation may also be because of the decreased trauma leading to a reduction in inflammation. ${ }^{9}$ This reduction in the incidence of postoperative arrhythmias, along with the reduction in the perioperative morbidity and in the intensive care unit and hospital lengths of stays, likely leads to a reduction in resource use.

The main limitation of our study is that it is a retrospective, single-center study. The surgical approaches were performed by 2 different teams of surgeons, which introduces a potential uncontrollable confounder. Furthermore, all minimally invasive operations were performed by a single surgeon (J.L.). Finally, the comparison of the surgical techniques was limited to in-hospital outcomes.

In conclusion, our study demonstrates the safety and feasibility of minimally invasive valve surgery in patients with CKD, which is associated with decreased postoperative complications, faster recovery, and reduced resource 
use. This approach should be considered as an alternative to standard median sternotomy valve surgery in this high-risk population.

\section{References}

1. Centers for Disease Control and Prevention (CDC). National Chronic Kidney Disease Fact Sheet: General Information and National Estimates on Chronic Kidney Disease in the United States, 2010. Atlanta, GA: US Department of Health and Human Services (HHS), CDC; 2010.

2. Sarnak MJ, Levey AS, Schoolwerth AC, Coresh J, Culleton B, Hamm LL, et al. Kidney disease as a risk factor for development of cardiovascular disease: a statement from the American Heart Association Councils on Kidney in Cardiovascular Disease, High Blood Pressure Research, Clinical Cardiology, and Epidemiology and Prevention. Circulation. 2003;108:2154-69.

3. Abbott KC, Agodoa LY. Hospitalizations for valvular heart disease in chronic dialysis patients in the United States. Nephron. 2002;92:43-50.

4. Lenihan CR, Montez-Rath ME, Mora Mangano CT, Chertow GM, Winkelmayer WC. Trends in acute kidney injury, associated use of dialysis, and mortality after cardiac surgery, 1999 to 2008. Ann Thorac Surg. 2013;95:20-8.

5. Ishani A, Nelson D, Clothier B, Schult T, Nugent S, Greer N, et al. The magnitude of acute serum creatinine increase after cardiac surgery and the risk of chronic kidney disease, progression of kidney disease, and death. Arch Intern Med. 2011;171:226-33.

6. Cohn LH, Adams DH, Couper GS, Bichell DP, Rosborough DM, Sears SP, et al. Minimally invasive cardiac valve surgery improves patient satisfaction while reducing costs of cardiac valve replacement and repair. Ann Surg. 1997;226:421-6.

7. Schmitto JD, Mokashi SA, Cohn LH. Past, present, and future of minimally invasive mitral valve surgery. J Heart Valve Dis. 2011;20:493-8.

8. Raja SG, Navaratnarajah M. Impact of minimal access valve surgery on clinical outcomes: current best available evidence. J Card Surg. 2009;24:73-9.

9. Mihos CG, Santana O, Lamas GA, Lamelas J. Incidence of postoperative atrial fibrillation in patients undergoing minimally invasive versus median sternotomy valve surgery. $J$ Thorac Cardiovasc Surg. 2012;pii: S0022-5223(12)01120-8.

10. Brown ML, McKellar SH, Sundt TM, Schaff HV. Ministernotomy versus conventional sternotomy for aortic valve replacement: a systematic review and metaanalysis. J Thorac Cardiovasc Surg. 2009;137:670-9.

11. Modi P, Hassan A, Chitwood WR Jr. Minimally invasive mitral valve surgery: a systematic review and meta-analysis. Eur J Cardiothorac Surg. 2008;34:943-52.
12. Lamelas J, Sarria A, Santana O, Pineda AM, Lamas GA. Outcomes of minimally invasive valve surgery versus median sternotomy in patients 75 years or greater. Ann Thorac Surg. 2011;91:75-80.

13. Santana O, Reyna J, Grana R, Buendia M, Lamas GA, Lamelas J. Outcomes of minimally invasive valve surgery versus standard sternotomy in obese patients undergoing isolated valve surgery. Ann Thorac Surg. 2011;91:406-10.

14. Mihos CG, Santana O, Lamas GA, Lamelas J. Outcomes of right minithoracotomy mitral valve surgery in patients with previous sternotomy. Ann Thorac Surg. 2011;91:1824-7.

15. Pineda AM, Santana O, Lamas GA, Lamelas J. Is a minimally invasive approach for re-operative aortic valve replacement superior to standard full resternotomy? Interact Cardiovasc Thorac Surg. 2012;15:248-52.

16. Levey AS, Coresh J, Balk E, Kausz AT, Levin A, Steffes MW, et al. National Kidney Foundation practice guidelines for chronic kidney disease: evaluation, classification, and stratification. Ann Intern Med. 2003;139:137-47.

17. Charytan DM, Yang SS, McGurk S, Rawn J. Long and short-term outcomes following coronary artery bypass grafting in patients with and without chronic kidney disease. Nephrol Dial Transplant. 2010;25:3654-63.

18. Howell NJ, Keogh BE, Bonser RS, Graham TR, Mascaro J, Rooney SJ, et al Mild renal dysfunction predicts in-hospital mortality and post-discharge survival following cardiac surgery. Eur J Cardiothorac Surg. 2008;34:390-5.

19. Kogan A, Medalion B, Kornowski R, Raanani E, Sharoni E, Stamler A, et al. Cardiac surgery in patients on chronic hemodialysis: short and long-term survival. Thorac Cardiovasc Surg. 2008;56:123-7.

20. Dasta JF, Kane-Gill SL, Durtschi AJ, Pathak DS, Kellum JA. Costs and outcomes of acute kidney injury (AKI) following cardiac surgery. Nephrol Dial Transplant. 2008;23:1970-4.

21. McCreath BJ, Swaminathan M, Booth JV, Phillips-Bute B, Chew ST, Glower DD, et al. Mitral valve surgery and acute renal injury: port access versus median sternotomy. Ann Thorac Surg. 2003;75:812-9.

22. Antonic M, Gersak B. Renal function after port access and median sternotomy mitral valve surgery. Heart Surg Forum. 2007;10:E401-7.

23. Schrier RW, Wang W. Acute renal failure and sepsis. N Engl J Med. 2004;351: 159-69.

24. Karkouti K. Transfusion and risk of acute kidney injury in cardiac surgery. $\mathrm{Br} J$ Anaesth. 2012;109(Suppl 1):i29-38

25. Murphy GJ, Reeves BC, Rogers CA, Rizvi SI, Culliford L, Angelini GD Increased mortality, postoperative morbidity, and cost after red blood cell transfusion in patients having cardiac surgery. Circulation. 2007;116: 2544-52. 